\title{
DEA MODEL FOR ASSESSMENT OF INSTITUTIONAL RESEARCH PRODUCTIVITY IN POLAND
}

\author{
Joanna JAKUSZEWICZ \\ Bialystok University of Technology, 15-351 Białystok, Wiejska 45A, Poland \\ E-mail: j.jakuszewicz@pb.edu.pl
}

Accepted 30 October, 2013

\begin{abstract}
The objective of the article is to present the model concept of measuring productivity in Polish research units through DEA method. It describes the instrument to support management of a research funding allocation by the Polish ministry.
\end{abstract}

Keywords: productivity, institutional assessment, Data Envelopment Analysis (DEA), Poland.

\section{INTRODUCTION}

Scientific achievements and prestige of scientists, scientific teams and institutions are a subject to a more scrutinised assessment process by different bodies. It is largely due to the growing role of science in the development of the knowledgebased economy as well as due to the common knowledge that the economic and social growth depend on the level of the research advancement and on the application of its results. High level and innovative research can become a driving force in the process of the country modernisation (King, 2004; Bonaccorsi et al., 2006; Coccia and Rolfo, 2008).

The evaluation of the research activity results is an important instrument in the organisational and financial management of research institutions. It becomes a crucial element in shaping the research policy and in implementing the research activities in different units of the research sector (Bernardin, 1996; Brennan and Shah, 2000; Brennan and Teichler, 2008). Evaluation and comparison of the research results improves the quality of science and creates a more competitive environment leading to wider openness of the research institutions to market needs and their greater flexibility in the co-operation with other research entities or units (Bonaccorsi et al., 2006).

Given the complexity of the research activity, the evaluation of research units on the national level is a difficult and complicated task. Scientific achievements or prestige of both individual researchers or research teams are a subject to diversified assessment methods. A traditional approach towards the evaluation of the level and the impact of the research achievements is expressed in a qualitative way and it is largely based on the opinions of other specialists in the relevant field of study. Currently, a range of criteria and methods for the research activity evaluation has increased due to the external pressure on the practical application of the research results (Butler, 2005; Guena and Martin, 2007; Coccia, 2008).

Since the early 70's in the research results management, more importance has been given to the questions of the research productivity and its evaluation, (Gates and Stone, 1997; Dundar and Lewis, 1998; Crespi and Geuna, 2004). A research unit can be characterized by means of inputs and outputs combined with the transformation processes which turn the resources into the results. Consequently, research productivity is understood as a result of the research activity in relation to the resources used for a given activity in a given period of time (Karlsson et al., 2004; WagnerDobler, 2005; Leydesdorff and Wagner, 2009; Vasileiadou and Vliegenthart, 2009). The main objective of the research productivity analysis is the evaluation of the research activity and the quality assessment.

\section{RESEARCH ASSESMENT IN POLAND}

The present paper uses data from the questionnaires submitted by all public scientific 
units in Poland to the Ministry of Science and Higher Education (MNiSW) covering the period between 2001-2004 and 2005-2010 (Polish Ministry of Science and Higher Education, 2010). On the basis of the submitted data, the MNiSW conducted a parametric assessment of the public scientific units. Public research units are composed of basic organisational units of higher education institutions (faculties), research institutions of the Polish Academy of Sciences, and non-university public $R \& D$ units. The research institutes are mainly public funded with the aim to produce scientific research according to the general guidelines set by MNiSW.

The parametric assessment and the categorisation resulting from this method constitutes a comparative system of the 'research production' of individual units. The system is based on the multiple outputs and as an input it considers a number of staff employed in a given unit to perform the scientific research and $R \& D$ activities.

Research outcomes of the parametric assessment are measured with regards to the two aspects: (1) results of research performance and entitlement to grant a $\mathrm{PhD}$ and $\mathrm{PhD}, \mathrm{DSc}$ and (2) practical implementations. Each field is represented by detailed variables. There are three different groups of variables dependent from research field of unit. These are: (a) humanities and social sciences, (b) technical science and (c) art sciences. In general, respectively (a) 21, (b) 31 and (c) 36 quantitative variables are considered to which numerical values were assigned, which determine the weight of the features.

For every research unit (j) partial index of efficiency $(\mathrm{Ej}, \mathrm{k})$ is calculated as a weighted sum of variables in each aspect $(\mathrm{k})$ as follows.

$$
E_{j, k}=\frac{\sum_{i=1}^{n_{k}} x_{j, i} v_{i}}{N_{j}}
$$

where:

$X_{j, i}-$ value of $i$-variable for $j$-unit

$v_{i}-$ weight of $i$-variable

$\mathrm{n}_{\mathrm{k}}$ - number of variables in the k-field

$\mathrm{N}_{\mathrm{j}}$ - number of R\&D employees for $\mathrm{j}$-unit

In each of the homogenous groups relative effectiveness indexes $\left(\mathrm{E}_{\mathrm{w}, \mathrm{j}, \mathrm{k}}\right)$ for each $\mathrm{k}$ group are determined.
They are obtained through referring partial efficiency indexes of the units to the highest index in the homogenous group.

$$
E_{w, j, k}=\frac{E_{j, k}}{\max \left(E_{j, k}\right)}
$$

$E_{j, k} \quad-$ partial index of efficiency for $j$-unit in $k$ group

The final index of efficiency is a weighted sum of the partial indexes. Every homogenous group has different weights.

$$
E_{j}=\sum_{k=1}^{a} E_{w, j, k} w_{k, g}
$$

$\mathrm{w}_{\mathrm{k}, \mathrm{g}} \quad$ - weight of partial index of efficiency for $\mathrm{k}$ field in the homogenous group $\mathrm{g}$.

Each of the groups was given a weight depending on its scientific specificity of the so called homogenous groups. At first, the Ministry classified the research units into 19 homogenous groups according to the type of research activity they specialised in.

The obtained efficiency indicators form a ranking basis within the homogenous groups and determine the assignment of an adequate research category. The range is based on a scale from 1 to 5 , which determines the distribution of financial resources for a research activity.

\section{DEA ANALYSIS}

For the evaluation of decision making units (DMUs) with multiple-inputs and multiple-outputs in a public sector, Data Envelopment Analysis (DEA) is now one of the most widely accepted methods to measure relative productivity of research institutions, (Print and Hattie, 1997; Kocher et al., 2006; Meng et al., 2007; Emrouznejad, 2008; Johnes and Yu, 2008; Cook and Seiford, 2009; Chen et al., 2010)..

The reliability of DEA models decreases if too many inputs or outputs are used. The selection of comprehensive indicators becomes difficult if stakeholders aim to achieve a relatively holistic evaluation as too many variables disturb differentiation of DMUs.

Yet a different problem is observed in the case of research units which want to apply the system of 
research unit evaluation to create their research policy or to mark out new fields of the research activity. At the beginning of the evaluation, many research units prove no output values.

This is especially the case in the evaluation of public research units in Poland, where many different outputs are measured in the evaluation in order to produce relatively comprehensive performance profiles of these institutes.

The rules of parametric assessment that have been used so far have risen many doubts in the academic environment, concerning their rationale, usefulness and the criteria of the assessment. Different examples of DEA method implementation lead to the conclusion that its application for the evaluation of Polish research units productivity is well justified, which is a purpose of the present paper.

\section{RESEARCH METHODOLOGY AND RESULTS}

The study of the methodology of parametric assessment was initiated with the sampling of the variables. The analysis covered 65 units of the homogenous group G1 - units representing mechanics, materials, chemical and processing engineering. As the input variable the number of R\&D staff was taken into consideration. The coefficients of variation were checked - all variables significantly differentiate the objects. The RGM method (Rybaczuk et al., 2007) was used in the initial correlation analysis (Figure 1).

The figure shows the relationship of objects to objects (in the middle of the circle) features to features (circle line) and the features to objects. Next, Spearman's correlation analysis disclosed that the part of the variables is highly correlated and these variables convey similar information. It means that the number of variables can be limited, because its excess set only seemingly improves diversification of the assessed units. Variables highly and insignificantly correlated with the input variable were excluded from the analysis. After the correlation analysis was carried out, the number of output variables was reduced to 5 variables.

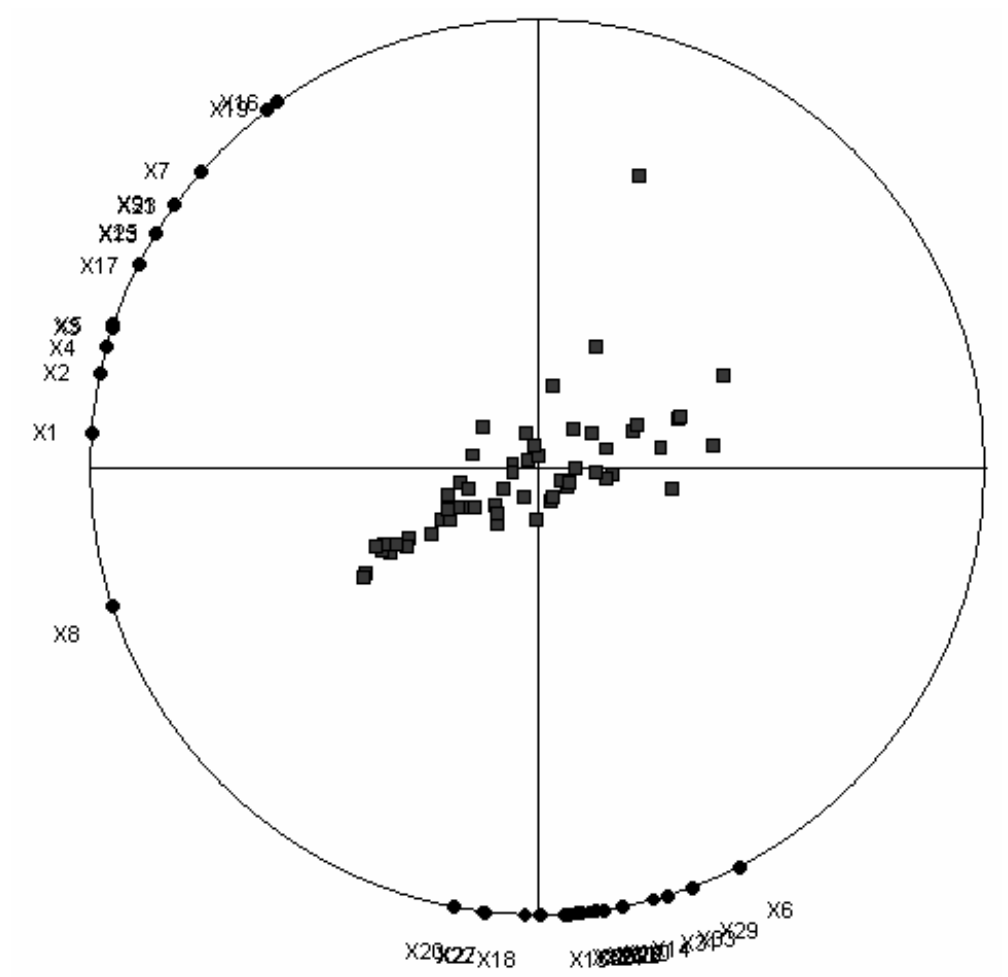

Figure 1: Illustration of the correlation analysis with RGM method (Source: Author's elaboration)

As a subsequent step the mechanism of factor analysis was applied. The factor analysis comprises a set of methods and procedures used to replace a big number of variables with a few insignificantly correlated factors. They keep relatively much information conveyed in the initial variables and at the same time each of them is a means of different merit content. 
As a result of the analysis two factors were obtained. The separated main components describe over $81 \%$ of variation of the data. The variables inside the factors are highly correlated, the variables were therefore isolated which are attributed by the highest factor weight. Later, while assigning them to the factors, two fields were determined, which should be takes into consideration in assessment of the research units.
For the sake of the further analysis a model with one input variable (Input1) - and two output variables (Ouput1), (Output2) were taken into consideration. This set of variables enables a clear graphic interpretation of the results in a twodimensional coordinate system (Figure 2).

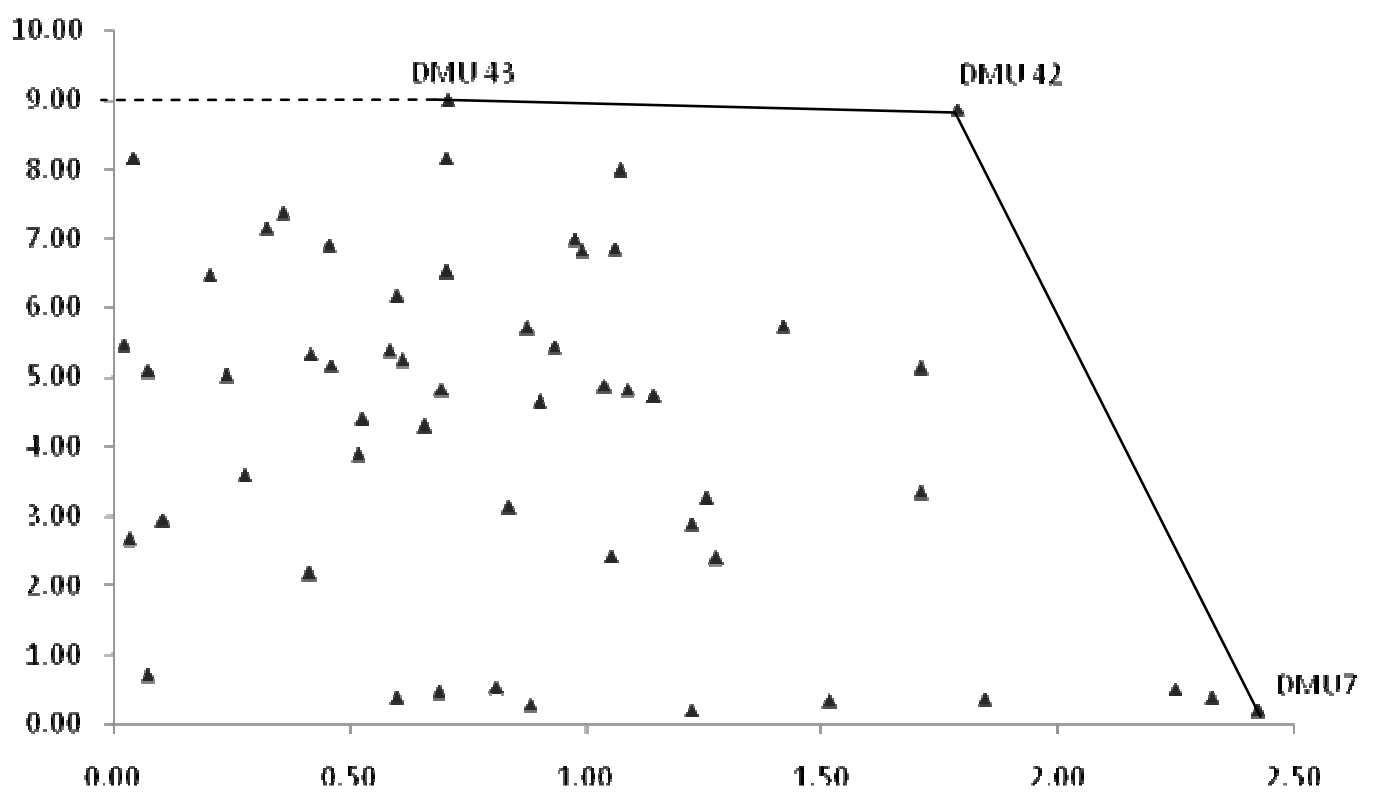

Figure 2: Illustration of the CCR model results

(Source: Author's elaboration)

The CCR and BCC output oriented models were used. The results have shown that the level of productivity is quite diversified. The mediane shows that productivity of the half of the units is below $66.10 \%$. The scientific units demonstrate also changeable economies of scale. Also comparison of two periods evaluation was done. On this basis setting the research categories could be more objective and clarified.

\section{CONCLUSION}

The author claims that the comparative analysis of productivity of research units with the DEA method can be a source of valuable managerial information, which could be the basis for scientific assessment in Poland. The application of the method may contribute to the increase of the objectivity of the weights which are currently arbitrarily assigned. It can also assess the level of the conducted scientific research and identify the units of a model efficiency level in national circumstances. A separate optimization for each unit exposes strengths of the unit determined by the resources and the environment. Furthermore it allows also to determine the so called "dead" resources, which do not influence significantly the results achieved by the unit.

The example used in the analysis has an illustrative character and requires further studies.

\section{REFERENCES}

Bernardin, H. J. (1996). Academic research under siege: toward better operational definitions of scholarship to increase effectiveness, efficiencies and productivity. Human Resource Management Review 6(3), 207-229.

Bonaccorsi, A., Daraio, C., \& Simar, L. (2006). Advanced indicators of productivity of universities (Italy). Scientometrics, 66(1), 389-410.

Brennan, J., \& Shah, T. (2000). Quality assessment and institutional change: Experience from 14 countries. Higher Education, 40(3), 331-349.

Brennan, J., \& Teichler, U. (2008). The future of higher education and of higher education research. Higher education looking forward: an introduction. Higher Education, 56(3), 259-264.

Butler, L. (2005). What happens when funding is linked 
to publication counts? In H. F. Moed \& al (Eds.), Handbook of Quantitative Science and Technology Research (pp. 389-405). The Netherlands: Kluwer Academic Publisher.

Chen, Y., Du, J., Sherman, H. D., \& Zhu, J. (2010). DEA model with shared resources and efficiency decomposition. European Journal of Operational Research, 207, 339-349.

Coccia, M. (2008). Measuring scientific performance of public research units for strategic change. Journal of Informetrics, 2(3), 183-194.

Coccia, M., \& Rolfo, S. (2008). Strategic change of public research units in their scientific activity. Technovation, 28(8), 485-494.

Cook, W. D., \& Seiford, L. M. (2009). Data envelopment analysis (DEA) - Thirty years on. European Journal of Operational Research, 192(1), 1-17.

Crespi, G., \& Geuna, A. (2004). The productivity of science. Brighton, UK: University of Sussex.

Dundar, H., \& Lewis, D. R. (1998). Determinants of research productivity in higher education. Research in Higher Education, 39(6), 607-631.

Emrouznejad, A., Parker, B. R., \& Tavares, G. (2008). Evaluation of research in efficiency and productivity: A survey and analysis of the first 30 years of scholarly literature in DEA. SocioEconomic Planning Sciences, 42(3), 151-157.

Gates, S., \& Stone, A. (1997). Understanding Productivity In Higher Education. Paper presented at the California Education Roundtable.

Guena, A., \& Martin, B. R. (2007). University Research Evaluation and Funding: And International Comparison. Minerva, 41(4), 277-304.

Johnes, J., \& Yu, L. (2008). Measuring the research performance of Chinese higher education institutions using data envelopment analysis. China Economic Review, 19(4), 679-696.

Karlsson, M., Trygg, L., \& Elfström, B. O. (2004). Measuring R\&D productivity: complementing the picture by focusing on research activities. Technovation, 24(3), 179-186.

King, D. A. (2004). The scientific impact of nations.
Nature, 430, 311-316.

Kocher, M. G., Luptacik, M., \& Sutter, M. (2006). Measuring productivity of research in economics: A cross-country study using DEA. Socio-Economic Planning Sciences, 40(4), 314-332.

Leydesdorff, L., \& Wagner, C. (2009). Macro-level indicators of the relations between research funding and research output. Journal of Informetrics, 3(4), 353-362.

Meng, W., Zhang, D., Qi, L., \& Liu, W. (2007). Twolevel DEA approaches in research evaluation. Omega, 36(6), 950-957.

Print, M., \& Hattie, J. (1997). Measuring quality in universities: An approach to weighting research productivity. Higher Education, 33(4), 453-469.

Polish Ministry of Science and Higher Education, Ustawa z dnia 30 kwietnia 2010 r. o zasadach finansowania nauki [The law on principles of financing science] (2010).

Rybaczuk, M., Nazarko, J., \& Czerniawska, M. (2007). Graficzna prezentacja struktury empirycznych danych wielowymiarowych: opis i zastosowanie metody [Graphical presentation of the empirical structure of multidimensional data: description and application methods]. Przeglad Psychologiczny, 50(3), 329-334.

Vasileiadou, E., \& Vliegenthart, R. (2009). Research productivity in the era of the internet revisited. Research Policy, 38(8), 1260-1268.

Wagner-Dobler, R. (2005). The system of research and development indicators (Germany). Scientometrics, l(62), 145-153

\section{AKNOWLEDGEMENT}

Research funded under the scientific grant No. $\mathrm{N}$ N115 294138 from the Ministry of Science and Higher Education in Poland (no. agreement 2941/B/H03/2010/38). 